\title{
Determinant Factors of Adoption of Introduced Soil Conservation Structures in North Gondar Zone, Ethiopia
}

\author{
* Mr. Tadewes Kassahun, ** Dr. Pujari Krishnaiah, \\ Masters Student, Department of Geography \& Environmental Studies, College of Social Sciences and \\ Humanities, University of Gondar, Ethiopia. \\ Associate Professor, Department of Geography \& Environmental Studies, College of Social Sciences and \\ Humanities, University of Gondar, Ethiopia.
}

\begin{abstract}
:
Soil erosion is a very severe problem in the highlands of Ethiopia, especially in Northern and central highlands of Ethiopia. In the country, efforts to conserve soil resources and prevent degradation dated back to the mid-1970s and 80s. However, the efforts put towards the promotion of the technologies, so far seem to have had limited impact in increasing the sustained use of conservation measures in different parts of the country, including Sabiya Sayna Kebele. The main purpose of this study was, therefore, to assess the sustainable use of physical conservation measures introduced through a major soil conservation.. Specifically, the study was conducted to assess farmers' perception towards the major introduced conservation structures; identify factors determining the adoption of these structures; and assess existing constraints to and options for sustained use of conservation structures in the study area. The study selected purposively of two sub-Kebeles where the recent intervention has already been implemented, and a total of 130 households were randomly selected from the sub-watersheds using the proportions-to-size technique of sample allocation. The study recommends that adequate consideration of the significant influential factors should be taken so as to better promote the sustainable use and widespread adoption of introduced conservation structures.
\end{abstract}

Key words: soil erosion, conservation structures, terrace, cut-off drain, soil bund, retention, adoption, determinants of adoption.

Back ground of the study:

In the present situation, depletion of natural resources is among the major problems facing human beings. A survey of soil degradation by the International Soil Reference and Information Center (ISIC) estimated that nine million hectares of land around the world are tremendously degraded; with their original biotic functions completely disappeared, and 1.2 billion hectares, i.e. $10 \%$ of the earth's vegetative surface, are at least moderately degraded (WRI, 2001). Worldwide inappropriate agricultural practices account for $28 \%$ of the degraded soils. About one fourth of them are found in Africa and Asia and nearly two thirds of the degraded soils in North America(WRI, 2001).

Soil conservation in Ethiopia is therefore not only closely related to the improvement and conservation of ecological environment, but also to the sustainable development of its agricultural sector and its economy at large. In Ethiopia, efforts towards this conservation goal were started since the mid-1970s and 80s (USAID, 2000). Since then, different soil conserving technologies with a varied approach has been underway. The focus was on the highland areas of the country where the problem is threatening and food deficit is prevalent. The conservation efforts were mainly undertaken through Food-for-Work (FFW) program benefits. World Food Program (WFP) and other governmental and non-governmental organizations (NGO) were supporting these projects and a great deal of money has been invested during the 1980s (Hurni, 1988). In the FFW program benefits, conservation measures on farmlands like construction of soil and stone bunds, fanaya juu, and tree planting on mountain areas have been introduced.

\section{Statement of the Problem:}


The Ethiopian economy is primarily dependent on agriculture. In any single year, agricultural production makes up more than 40 percent of the GDP. Much of the foreign currency earnings are derived from it and some $85 \%$ of the country's population derives their livelihood directly from the sector. Small land hold farmers operating under entirely rain-fed condition dominate the sector. Small land holders account for $95 \%$ of the total area under crop cultivation. And they contribute more than $96 \%$ of the total agricultural output (Isaksson, 1994). Despite its role, the sector is characterized by low productivity and high exposure to risk due to adversely varying environmental conditions (Bezabih, 2000). The ecological discrepancy the country is facing serious challenges these days. Annual agricultural production cannot keep pace with the growing number of the population (WORLD BANK, 1995) and this exposed the country's agricultural population to food insecurity. Currently, Ethiopia is experiencing a wide food disparity with the food demanded and the food supplied from domestic production.

In the study area, farmers are confronted with low availability of productive resources on the one hand and lack of other employment options on the other. This has led to a continuous fragmentation of landholdings. Literature on agricultural intensification states that as key resources such as land become scarce, humans may adjust over time by increasing labor efficiency, substituting other resources, innovating new technologies, creating new resource management institutions, or implementing conservation (Dodds, 1998). For instance, reductions in soil fertility and crop yield may encourage behaviors that intensify production, such as shortening of fallows, adoption of new crops and technologies (Boserup,1965, Cited in Abera, 2003). Unlike this Boserup hypothesis a huge population pressure on the available land resource in the study area makes hardly possible to exercise land-conserving practices. This is because farmers have no time for adjustment. Thus, land is over utilized and eroded and its productive capability is diminished.

\section{Methodology \\ Location of the study area:}

This study was conducted in sabiya sayna Kebele in North Gondar zone of Amhara National Regional State (ANRS), Ethiopia. Geographically, the study area is found at 1402274-1402529 Northings and 03370260337995 Easting. The topography of the district comprises altitudes ranging between 2000 and 2600 meters (m) above sea level.

Method of Data Collection:

Primary and secondary data was collected in the study. Secondary data, particularly data on socio-economic profile and physical description of the study area, collected from the archives and reports of organizations at different levels: Zone, district, and PA level. On the other hand, the study was utilized a multitude of methods for primary data collections so as to suit the objectives of this study. The methods include: formal household survey, group discussion, key informant interview and filed observation. Table 3 provides an overview of research methods and sampling techniques applied in order to obtain information concerning the specific research objectives.

\section{Sample size and Sampling technique:}

Total sample size was determined using the following formula (Cochran, 1977):

$$
n_{0}=\frac{Z^{2} p q}{d^{2}} \rightarrow n=\frac{n_{0}}{1+\frac{n_{0}-1}{N}}
$$

$\mathrm{n}_{0}$ is the desired sample size when the population is greater than 10000

$\mathrm{n}$ is number of sample size when population is less than 10000

$\mathrm{Z}$ is $95 \%$ confidence limit i.e. 1.96

$\mathrm{p}$ is 0.1 (proportion of the population to be included in the sample i.e. $10 \%$

$\mathrm{q}$ is $1-0.1$ i.e. (0.9)

$\mathrm{N}$ is total number of population (442 households)

$\mathrm{d}$ is margin of error or degree of accuracy desired (0.05)

According to the above formula, the resulting sample size was 106. Hence, a total of 130 households (106 plus additional samples for contingency) was selected using a simple random sampling techniques. However, the allocation of sample size across the two sample sites was made based on the proportional to 
size techniques of sample allocation: 76 households from Aba Golem (260 total household) and 54 from Bukaya Sheleko (182 total household).

Data Analysis:

First, the data collected from survey was checked carefully, and coded and entered into excel. To meet the objectives of the study, both descriptive and inferential analysis was used by using statistical package for social science for windows 16 (SPSS, 2012). Descriptive statistics was used for describing socio-economic characteristics of sample respondents, and to analyze those data concerning perception and management issues. These statistics include frequencies, proportions or percentages, averages and others.

Inferential statistics was used to study relationships between variables using t-test, chi-square, and regression analysis. Independent t-test was used to detect differences in the mean of one variable between two groups of respondents, whereas, the Chi-square test was used to detect any systematic association between the dependent variable of interest and specific household characteristics.

Model Specification:

To answer the question of factors influencing farmers' decision to adopt the introduced Soil Conservation practices, the econometric model was used. The required model for this study is a model that reflects the observed status of introduced soil conservation structures on any particular farm. Such observations reflect a dichotomous variable, retaining/adopting or not retaining/adopting conservation structures. Therefore, such dichotomous variable was regressed against potential factors by using a binary logit regression model. A justification behind the use of logistic model isincluding its closer approximation to the cumulative normal distribution; extremely flexible, from a mathematical point of view, and easily used function; and it lends itself to a meaningful interpretation.

The logistic distribution function, according to Gujarati (2004), for identification of the adopter and nonadopter farmers can be defined as:

$$
P_{i}=\frac{1}{1+e^{-z_{i}}} \quad
$$

Where $\mathrm{Pi}$ is the probability of being adopter for the $\mathrm{i}^{\text {th }}$ farmer and $\mathrm{Zi}$ is a function of $m$ explanatory variables (Xi) (discussed below), and expressed as:

$$
Z_{i}=\beta_{0}+\beta_{1} X_{1}+\beta_{2} X_{2}+\cdots+\beta_{m} X_{m}
$$

Where $\beta_{0}$ is the intercept and $\beta_{\mathrm{i}}$ are the slope parameters in the model. The slope tells how the log-odds in favor of being adopter of Soil Conservation change as independent variables change. Since the conditional distribution of the outcome variable follows a binomial distribution with a probability given by the conditional mean $\mathrm{P}_{\mathrm{i}}$, interpretation of the coefficient was understandable if the logistic model can be rewritten in terms of the odds and log of the odds, (Gujarati, 2004).

The odds to be used can be defined as the ratio of the probability that a farmer was adopt (Pi) to the probability that he/she was not (1-Pi).But,

$$
1-P_{i}=\frac{1}{1+e^{z_{i}}}
$$

Therefore,

$$
\frac{P_{i}}{1-P_{i}}=\frac{1+e^{z_{i}}}{1+e^{-z_{1}}}=e^{z_{l}}
$$

$\begin{aligned} & \text { And, } \\ & \frac{P_{i}}{1-P_{i}}\end{aligned}=\frac{1+e^{Z_{i}}}{1+e^{-Z_{i}}}=e^{\beta_{\mathrm{e}}}+\sum_{i=1}^{m} \beta_{i} X_{i}$ 
Taking the natural logarithm of the odds ratio of equation (5) was result in what is known as the logit model as indicated below:

$\operatorname{Ln}\left[\frac{P_{i}}{1-P_{i}}\right]=\operatorname{Ln}\left[e^{\beta_{\mathrm{o}}}+\sum_{i=\mathbf{1}}^{m} \beta_{i} X_{i}\right]=e^{z_{i}}$

If the disturbance term Ui is taken into account the logit model becomes:

$Z_{i}=\beta_{\mathrm{o}}+\sum \beta_{i} X_{i}+U_{i}$

Socio-Economic Description of Respondents:

Table:. Summary of Age and Family size of respondents

\begin{tabular}{|c|c|c|c|c|c|c|c|}
\hline & & \multicolumn{2}{|c|}{$\begin{array}{c}\text { Non-adopter } \\
(\mathrm{N}=48)\end{array}$} & \multicolumn{2}{|c|}{ Adopter $(\mathrm{N}=72)$} & \multirow[t]{2}{*}{$\mathbf{t}$} & \multirow[t]{2}{*}{$\mathbf{p}$} \\
\hline & $\begin{array}{l}\text { Total } \\
\text { Mean }\end{array}$ & Mean & SD & Mean & SD & & \\
\hline Age of HH head & 49.42 & 54.27 & 18.065 & 46.18 & 10.086 & 3.14 & 0.002 \\
\hline \multicolumn{8}{|l|}{ Family Size } \\
\hline Total & 5.47 & 5.08 & 2.191 & 5.74 & 1.538 & -1.918 & 0.058 \\
\hline $\begin{array}{l}\text { Number of } \\
\text { members of } \\
\text { Working age }\end{array}$ & 3.73 & 3.52 & 1.879 & 3.88 & 1.686 & -1.076 & 0.284 \\
\hline $\begin{array}{l}\text { Number of } \\
\text { Dependent } \\
\text { members }\end{array}$ & 1.73 & 1.56 & 1.443 & 1.85 & 1.252 & -1.148 & 0.253 \\
\hline $\begin{array}{l}\text { Consumer to } \\
\text { worker } \\
\text { Ratio }\end{array}$ & .6334 & .5934 & .58770 & .6600 & .61464 & -0.592 & 0.555 \\
\hline
\end{tabular}

The family size of the total sample respondents, on average, was 5.47 with a range from 2 to 9 persons. The study observed the existence of variation in family size between adopter and non-adopter, whereby, the mean family size of adopter and non-adopter households was found to be 5.74 and 5.08, respectively. According to the t-test analysis result, the mean family size of adopters was significantly $(\mathrm{p}<0.1)$ greater than that of non-adopters. Variation was also observed in the average number of worker and consumer/dependent family members. With a total average value of 3.73 persons, mean number of workers was found to be 3.52 for non-adopters and 3.88 for adopter households. On the other hand, with a total average value of 1.73, mean number of consumer/dependent family members was 1.56 and 1.85 , respectively, for non-adopter and adopter households. This indicates that adopter respondents, as compared to the non-adopter ones, had a higher mean of number of worker and consumer/dependent family members. However, a statistically significant variation was not found for such observed differences.

One of the important demographic characteristics is consumer to worker ratio. It is normally the ratio of total number of consumers/dependents to workers or economically active members of the household. According to the survey result of the current study, average consumer to worker ratio of the total sample households was 0.633 . With respect to adoption, the average ratio for adopter respondents was found to be 0.66 , whereas, for non-adopters, it was 0.63. Important point to mention here is that the ratio value observed in both cases was below unity which implies that members of working age group (15-64 years) comprise greater proportion of a household. This has a considerable role in accomplishment of multitude of activities with a varying labor requirement, particularly activities related to establishment and maintenance of conservation measures. Contrastingly, in the current study, average consumer to worker ratio was higher for adopter households than for non-adopters, implying that shortage of labor resource is relatively less for the latter than the former households. However, no statistically significant variation in the mean ratio was observed between adopters and non-adopters. 
Table: Educational status of respondents:

\begin{tabular}{|c|c|c|c|c|c|c|}
\hline & \multirow{2}{*}{$\begin{array}{c}\text { Total } \\
(\%)\end{array}$} & & \multicolumn{2}{|c|}{ Adoption } & \multirow[b]{2}{*}{ Chi-square } \\
\hline & & & & $\begin{array}{c}\text { Non- } \\
\text { adopter }\end{array}$ & Adopter & \\
\hline \multirow[t]{4}{*}{ EDUC } & \multirow[t]{2}{*}{ Illiterate } & \multirow[t]{2}{*}{43.3} & $\%$ within EDUC & 42.3 & 57.7 & \multirow[t]{4}{*}{0.00 (NS) } \\
\hline & & & $\begin{array}{l}\% \text { within } \\
\text { adoption }\end{array}$ & 45.8 & 41.7 & \\
\hline & \multirow[t]{2}{*}{ Literate } & \multirow[t]{2}{*}{56.7} & $\%$ within EDUC & 38.23 & 61.77 & \\
\hline & & & $\begin{array}{l}\% \text { within } \\
\text { adoption }\end{array}$ & 54.2 & 58.3 & \\
\hline
\end{tabular}

\section{Land and its Characteristics:}

Sample respondents owned farm lands with total size ranging from 0.5 to 4.75 ha. On average, land holding size per household was 1.51 ha (Table 8). According to the survey result, adopter households had relatively higher landholding size (1.52 ha) than non-adopters though such variation was found insignificance as to the independent sample t-test analysis.

Assessment of Use of Soil Conservation Structures:

Households' Perception towards the change in production and its causes:

The declining trend of agricultural production, as reported elsewhere in Ethiopia, was indicated to be occurred in the study area. In the current study, households pointed out that the crop yield of their farms is declining from year to year, and that problem of food insecurity has become more apparent in the area. Different factors were indicated as causes for the declining crop production, and its subsequent problem of food insecurity. These include soil degradation, low rainfall amount, erratic rainfall and land shortage. Soil degradation was the major factor reported by greater proportion of the respondents. 95\% of sample households mentioned soil erosion as the underlying cause for deterioration of productivity of their farmland.

Households' perception towards the problem of soil erosion and its causes:

About $95 \%$ of the sample households perceived that there is at least low level of soil erosion problem on their cultivated land and this indicate soil erosion as a major problem they are facing with this. The remaining $5 \%$ of farmers indicated that there is no erosion problem on their farm land. This is more than to the findings of other studies made in different part of the country. For instance, Abera (2003) found that about $81 \%$ of farmers interviewed perceived soil erosion problem on their cultivation field.

In the study area the perception of farmers about the degree of the problem of soil erosion is different among respondents. About $74.2 \%$ of farmers interviewed indicated that there is moderate or severe erosion problem on their farmland and $20.8 \%$ of farmers interviewed rated the problem to be low on their cultivation land. The majority of household survey result (about 44\%) indicated that there is moderate level of erosion problem on their farm land and the remaining 30\% indicated that there is severe erosion problem.

Table : Farmers' Perception of Degree of Erosion Severity on their cultivation land

\begin{tabular}{|l|c|c|}
\hline Degree of erosion & Frequency & \% \\
\hline No Erosion & 6 & 5 \\
\hline Low Erosion & 25 & 20.8 \\
\hline Moderate Erosion & 53 & 44.2 \\
\hline Severe Erosion & 36 & 30 \\
\hline Total & 120 & 100 \\
\hline
\end{tabular}

The majority of farmers' perceptions, about causes' of soil erosion on their farm land through time are human and natural factors. Cultivation of land without fallowing was indicated by about $64 \%$ of the respondents as one of the important causes of erosion followed by deforestation or vegetation removal (about 55\%). Besides, cultivation of sloppy or marginal lands also has received a considerable attention and 
indicated by $52 \%$ of the total sample respondents. The other indicated causes of soil erosion were overgrazing and flooding.

Introduced Soil Conservation Practices and the Approach to their Promotion:

Majority of soil conservation effort made in the area was directed to controlling soil loss from cultivated fields. Different types of conservation measures were introduced to the study area. They were introduced with objectives of conserving, developing and rehabilitating degraded agricultural lands and increasing food security through increased food production/ availability. The majority of conservation measures introduced to the area are mechanical conservation measures. According to information obtained from informants that Implementation of all soil conservation structures was limited to dry seasons (from January up to march) so as to interfere with too numbers of farmers and to avoid difficulty of limited labor access. Major introduced soil conservation structures in the study area were terrace, soil bund, Cut off drain and check dam .

Table : Major introduced conservation structures and their state of adoption

\begin{tabular}{|l|l|c|c|}
\hline Structures & & Frequency & \% \\
\hline \multirow{5}{*}{ Terrace } & Never use & 17 & 14.2 \\
\cline { 2 - 4 } & $\begin{array}{l}\text { Complete } \\
\text { destruction }\end{array}$ & 40 & 33.3 \\
\cline { 2 - 4 } & Some destruction & 19 & 15.8 \\
\cline { 2 - 4 } & Retained & 44 & 36.7 \\
\cline { 2 - 4 } & Total & 120 & 100 \\
\hline \multirow{5}{*}{ Soil bund } & Never use & 8 & 6.7 \\
\cline { 2 - 4 } & $\begin{array}{l}\text { Complete } \\
\text { destruction }\end{array}$ & 55 & 45.8 \\
\cline { 2 - 4 } & Some destruction & 47 & 39.2 \\
\cline { 2 - 4 } & Retained & 10 & 8.3 \\
\cline { 2 - 4 } & Total & 120 & 100 \\
\hline & Never use & 54 & 31.7 \\
\cline { 2 - 4 } & $\begin{array}{l}\text { Complete } \\
\text { destruction }\end{array}$ & 38 & 18.3 \\
\cline { 2 - 4 } & Some destruction & 6 & 100 \\
\cline { 2 - 4 } & Retained & 22 & \\
\cline { 2 - 4 } & Total & 120 & \\
\hline
\end{tabular}

Description of Introduced SC structures:

\section{Terrace:}

The embankment or ridge constructed across a slope along the contour. On steep eroded bare lands stone terraces are most used structures in study area. As it is stated by key informants during focus group discussion the stone terraces are considered effective in order to reduce the runoff on a steep sloping land erosion control in steeply areas (Figure 1a).

The survey result showed that $86 \%$ of the sample household has been using terrace as one of soil conservation measures (Table 18). However, 33.3\% of such user households have made a complete destruction immediately or some period after constructing the structure (Figure b). The other 15.8\% of user households were found to make some destruction of the terrace structure, while the remaining $44 \%$ has still retain the structure. The result that one-third of the sample respondents destructed or removed the entire constructed terrace indicates the existence of problems. Moreover, the observed occurrence of 'some destruction' in this study may manifest that the sustainability of the remaining retained structures is not certain. 


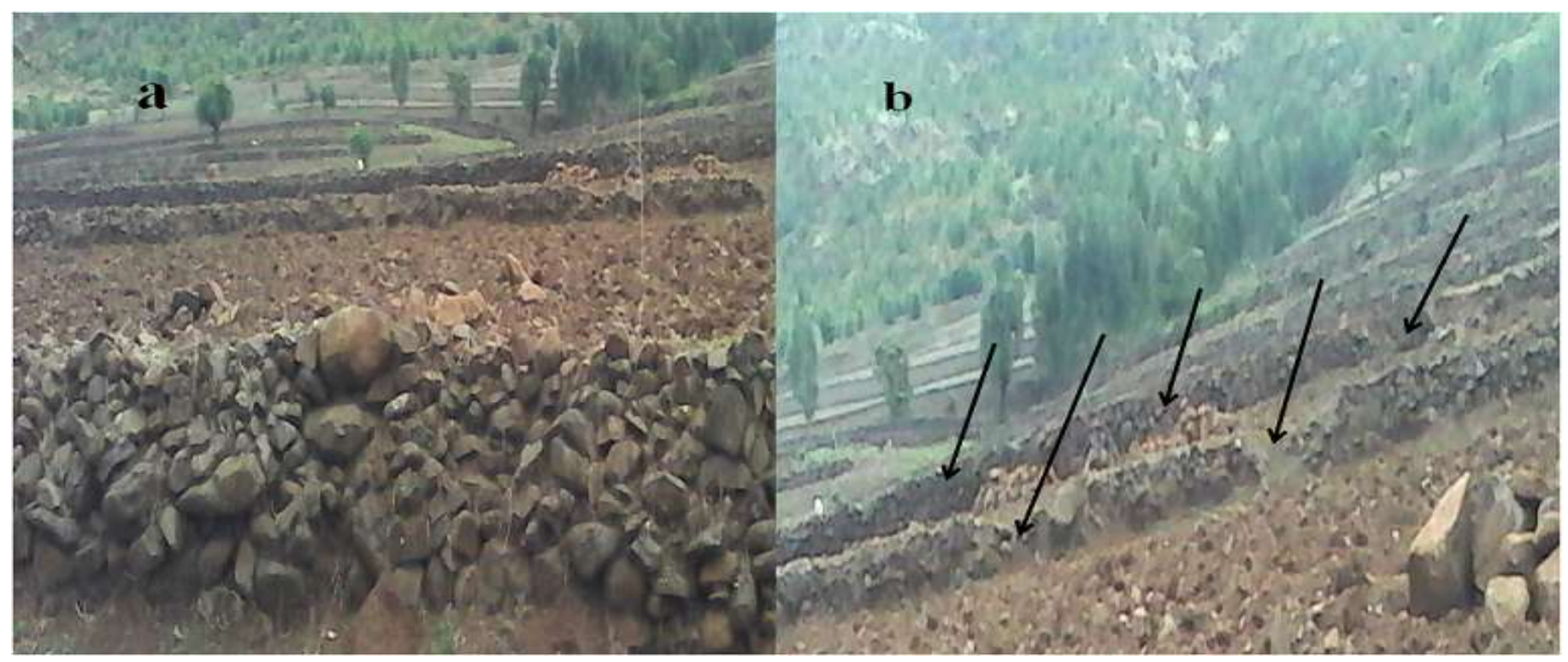

Figure1 : a- Retained and b- Destructed (Arrows) Stone terraces

\section{Soil bund}

They are constructed by throwing soil dug from basin down slope. And the embankments constructed from soil along the contour with water collection channel or basin at its upper side.In the study area, soil bund introduced on farm land to control runoff and erosion from cultivation fields by reducing the slope length of the field which ultimately reduces and stops velocity of runoff.

Among the total sample respondents, only $6.7 \%$ of them have never adopted soil bund, whereas, $93.3 \%$ were found to use the structure out of which $45.8 \%$ completely removed the structure, $39.2 \%$ removed some and the remaining $8.3 \%$ retained structures in their original state (Table 18). Even though proportion of non-user households for soil bund is less than for terrace, proportion of households with some as well as complete destruction is higher in the case of soil bund than in terrace. Figure c illustrates a destructed soil bund in the study area. Likewise, retention is more apparent for terrace than soil bund. This may be attributed by, regardless of factors related to households, the difference between these structures in resisting physical obstructions such as rain, run-off, livestock etc. The extent of using soil bund in the study area is relatively less than that reported in some other areas. For instance, Fikru (2009) reported 61\% adopter households in Koga watershed, which is by far more than the proportion found in this study, $47.5 \%$ (Retained plus Some destruction).

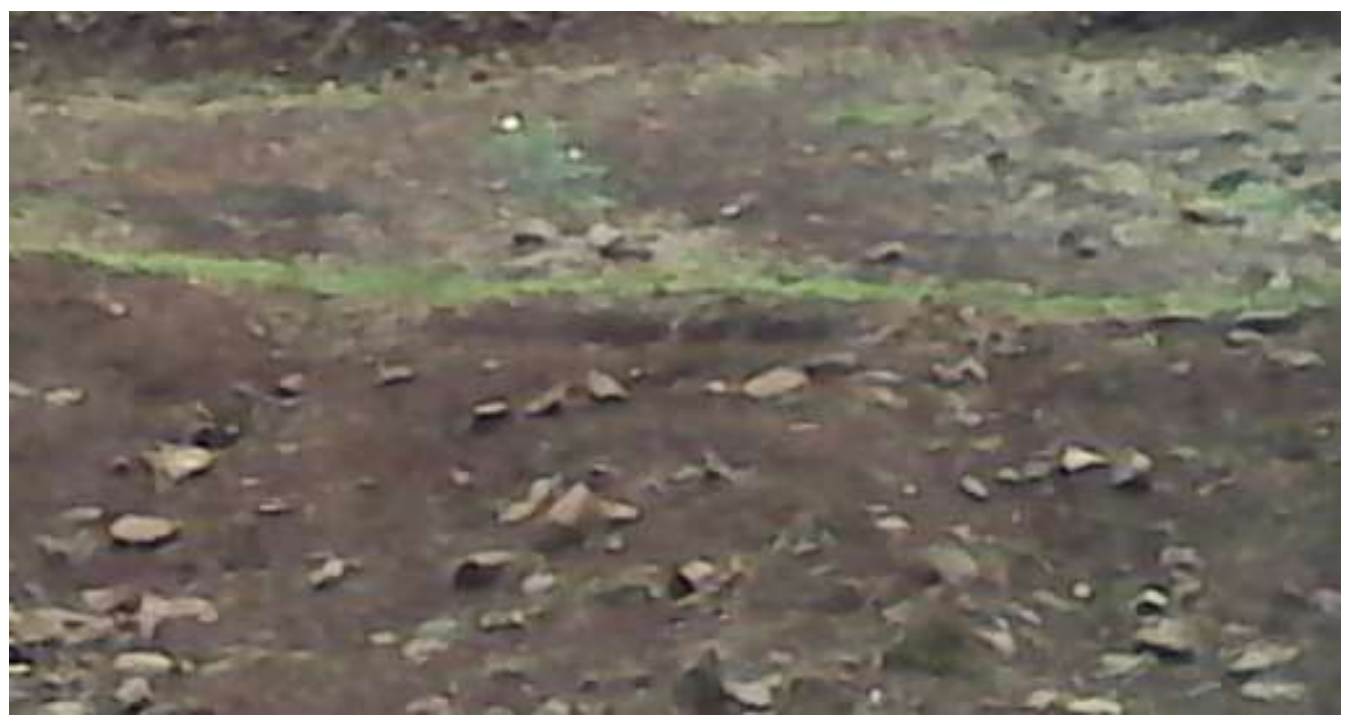

Figure.c Destructed Soil bund in the study area

\section{Cut off drain}

Cut off drain are one of the physical structure constructed by digging the soil deep in order to divert the runoff before reaching the farmland and to prevent loss of seeds, fertilizer and soil due to excessive run- off 
coming from uplands and dispose the excess water for the field. However, according to information obtained from informants these structures are accelerating soil erosion. During a transect walk with DAs gulliesassociated with the construction of these structure especially, between the boundaries of plots, were commonly observed.

It was only about half of (55\%) the respondents that has been using cut of drain on their farm land. Majority of these respondents $(31.7 \%)$ have even completely destructed the conservation structure, while the remaining $5 \%$ and $18.3 \%$ of them have, respectively, made some destruction and retained the structure (Table 18). The low extent of adoption of cut off drain, as compared to the other, indicates the existence of problems. Information obtained during group discussion revealed some of the drain structures enhance soil erosion through time. Such problem was also confirmed by the observation from transect walks where several gullies between farm boundaries started by the cutoff drains were observed.

Generally, though variation exists among the three structures, the most common response of sample households to the introduced conservation measures was complete destruction. Other similar studies have also reported a comparable result. For instance, Bekele (1998) found 53\% of households who removed introduced measures completely, and Habtamu (2006) reported that about 53\% of the interviewed farmers removed conservation structures completely. Likewise, Woldeamlak (2003) found that $78 \%$ of farmers interviewed do not have plan/ intention to implement introduced conservation structures.

Conclusion

This study was conducted in Sabya sayna Kebele to address three major objectives: assess farmers' perception towards the major introduced conservation structures; identify factors determining the adoption of these structures; and assess existing constraints to and options for sustained use of conservation structures in the study area. The study area is characterized by steep and undulating terrain which is susceptible to soil erosion, and it receives heavy rain. Besides, livelihood of the society is heavily dependent on rain-fed agriculture, mainly on production of crops requiring fine tilled soil. Such and other similar situations are explicit justifications for soil and water conservation intervention. In this regard, a range of conservation measures were introduced in the study area with the objective of conserving, developing and rehabilitating degraded agricultural lands and increasing food security through increased food production/ availability. Majority of the conservation measures have been applied on cultivated fields and all of them are physical conservation measures. The three most commonly introduced structures are terrace, soil bund and cut off drain.

\section{Recommendations:}

The following points are recommended based on the findings of this study:

1. Most of conservation technologies introduced to the area are physical conservation measures, and in short term returns from this conservation package might be negative. Hence, putting much focus on these physical conservation measures is less likely to be important. Rather, it is important to integrate these measures with indigenous soil conservation measures and measures that provide economic return in short term.

2. It should be considered that conservation structures need to be made appropriate by making them to be less labor demanding and not taking as large land as it is taking now.

3. The role of agricultural extension in promoting adoption of soil conservation is remarkable, as confirmed by the study's empirical finding. Therefore, extension services should be promoted so as to be delivered for more households, and also improvement of the existing way of delivery, to make it more efficient, is important.

4. The negative relationship between access to off-farm employment and adoption calls for the need to look for suitable continuous incentives that support farmers engaging in maintenance and sustainable use of the structures. This may alleviate the labor competition for satisfying consumption requirements.

5. Perceiving traditional conservation measures as ineffective to retain soil loss has an encouraging effect on the decision to adopt more effective conservation structures. Therefore, advocating and disseminating information about ineffectiveness of traditional conservation measures is very important, particularly for those who heavily relay on traditional conservation measures. 
6. Moreover, adequate consideration of the significant influential variables should be taken so as to better promote the sustainable use and widespread adoption of introduced conservation structures.

7. Prevalence of rodents; obstruction in farming operations; and making scarce land out of cultivation are major important constraints related to conservation structures. Therefore, further investigation should be made so as to alleviate such problems and develop the most

8. Effective combination of conservation structures that are complimentary for crop production.

\section{References:}

[1] Abera, B. 2003. Factors influencing the adoption of soil conservation practice in north western Ethiopia.

[2] Adams, M. 2001. Tenure security, livelihoods and sustainable land use in Southern Africa. Presented at SARPN conference on Land Reform and Poverty Alleviation in Southern Africa, Pretoria

[3] Bekele S, (1998). Peasant Agriculture and Sustainable land use in Ethiopia. Economic Analysis of Constraints and Incentives for Soil Conservation. Agricultural University of Norway. Dissertation no: 1998:1.

[4] Colman, D. 1993. Principles of agricultural economics: Markets and prices in less developed countries: Cambridge University Press

[5] Dodds, D.J. 1998. Population growth and forest cover change in the Río Plátano Biosphere Reserve, Honduras. Available at:

[6] Girma (2001). A Participatory Aproach to Agroforestry in Watershed Management:A Case study at Yanessie, Southern Ethiopia. Unpublished MA thesis. Wageningen University, Wageningen

[7] Keil, A. 2001. Adoption of leguminous tree fallows in Zambia. Discussion paper No. 33. Universität Göttingen, Germany

[8] Long L (2003). Conservation Practices Adoption by Agricultural Land Owners. PhD Dissertation. Northern Illinois University. Delealb, Illinois.

[9] Ntegn, N. 1997. An assessment of factors affecting adoption of maize production technologies in Iganga District, Uganda. Addis Ababa, Ethiopia, NARO/CIMMYT

[10] Pretty J. N and Shaha. P, (1996). Making Soil and Water Conservation Sustainable:From Coercion and Control to Partnerships and participation. Land Degradation and Development 8: 39-58.

[11] World Bank; World Development Report 2003; Oxford University Press, New York; 2003.

[12] Yohannes, G. 1994. Watershed and household level approach in the analysis of the sustainability of introduced physical SWC measures in Ethiopia. Presented at 8th International Soil Conservation Conference, India 